\title{
A AMIZADE INFANTIL E A TIRANIA DO MUNDO DOS ADULTOS EM "A ILHA DOS GATOS PINGADOS"
}

\author{
Pedro Paulo Gomes Santos ${ }^{1}$
}

RESUMO: Neste artigo, o conto "A ilha dos gatos pingados" do escritor José Jacinto Veiga, ao tratar o tema traz uma proposta pela vertente romanesca do Realismo mágico. A partir de tais indagações, o trabalho propõe-se discutir a violência cometida contra crianças, bem como a tirania dos adultos sobre elas. Também, analisar se o lar é um ambiente que transmite segurança; também sugere trabalhar este conto em sala de aula para valorizar os aspectos estéticos do texto literário e inter-relacioná-los aos aspectos sociais e políticos de um determinado grupo. O trabalho consiste em pesquisa bibliográfica de análises do conto/crônica proposto e de autores que discutem as problemáticas apresentadas. Disto, conclui-se que o conto "A ilha dos gatos pingados" de J. J. Veiga, além de promover prazer estético da leitura, pode-se também abrir espaços para discussões temáticas a respeito de assuntos controversos como: amizade, solidariedade, violência que incide em humilhações e agressões.

PALAVRAS-CHAVE: Conto. Literatura. Violência. Crianças.

\section{INTRODUÇÃO}

Procuramos discutir o tema violência doméstica a luz do conto " a ilha dos gatos pingados" (1959), onde o autor trata com frequência a violência sofrida por crianças e adolescentes no âmbito familiar e que na maioria das vezes acabam tendo que afastar-se de seu lar, este ambiente deveria ser um lugar que lhe proporcionasse segurança e proteção, acaba se transformando em um ambiente vulnerável e por se sentir inseguro muitos passam a viverem as margens das ruas onde muitas vezes são transformados em marginais, prostitutas, ladrões e traficantes.

José Jacinto Veiga neste conto nos traz a temática sobre a violência doméstica e o bullying, ao mesmo tempo nos faz refletir sobre estes problemas que assolam a nossa sociedade, discutir este tema é de real importância em nossa sociedade e envolve a participação dos pais, professores, alunos e a sociedade. Ao abordar esta temática com alunos da rede pública federal muitos destes apontaram que as soluções para os problemas só serão possíveis mediante a reeducação da sociedade sobre as temáticas vividas nestes dias.

Para muitos alunos desta instituição o conto aborda o bullying como um problema da sociedade onde tanto o agressor bem como os que estão próximos, os quais não agride com palavras, mas a sua ação é predominante se tornam passivos, o agressor ao fazer qualquer tipo de desfeita em relação a uma pessoa, alguém ou o grupo ao escarnecer estão participando do bullyings e a pessoa que sofre acaba tendo reações fortes. Neste conto são apresentados fatos

1 Orcid: https://orcid.org/0000-0002-6951-9893,E-mail: pecipa@yahoo.com.br 
que acontece com um dos personagens que sempre foi evitado no grupo e a sua reação foi de vingança pela sua não aceitação.

Toda vez que a gente queria ir em algum lugar precisava combinar escondido, sair sem Camilinho ver, e às vezes nem assim adiantava. Quando a gente ia longe, lá vinha Camilinho correndo atrás, chorando e pedindo pra esperar. Tenisão xingava, jogava pedra, mas ele não desistia. Era preciso parar e esperar. (VEIGA,2015: p.27)

O bullying se faz presente fortemente até entre as próprias crianças e isto se dar quando a idade não condiz com o do grupo e quando existe a possibilidade de não conseguir acompanhar o grupo no qual ele se apresenta. É preciso discutir isto em nosso século e em nossa geração, pois ela tem aflorado cada vez mais.

\section{CONCEITUANDO A VIOLÊNCIA}

Violência é uma manifestação abusiva de poder capaz de ignorar, ofender, humilhar, oprimir, explorar, machucar e até mesmo matar.

Para Azevedo \& Guerra, “... é uma relação interpessoal, assimétrica e hierárquica de poder com fins de dominação, exploração e opressão ... de um lado está o polo adulto, mais forte (o abusador) e de outro está o polo infantil, mais fraco (o vitimizado)". (AZEVEDO; GUERRA, 2000, p.102).

A violência causa transtornos que são irreparáveis as pessoas que sofrem a ação e impossibilita qualquer reação pois são dominados pela ação do mais forte daquele que exerce o poder opressor.

O termo violência doméstica se usa quando agressores - pessoas que detém a autoridade, o poder e / ou a força física - tem com suas vítimas uma relação de consanguinidade, de afinidade e /ou de responsabilidade. Violência doméstica contra crianças e /ou adolescentes é todo ato ou omissão praticado por pais, parentes ou responsáveis contra crianças e/ou adolescentes que - sendo capaz de causar dano físico, sexual e/ou psicológico à vítima - implica, de um lado, em uma transgressão do poder/dever de proteção do adulto e, de outro, numa coisificação da infância, isto é, numa negação do direito que crianças e adolescentes tem de ser tratados como sujeitos e pessoas em condição peculiar de desenvolvimento.

(AZEVEDO; GUERRA, 2000: p.12)

O maior problema da violência se encontra presente no ambiente doméstico, ou seja, esta se manifesta no próprio lar, é na própria família que se encontra os agentes da violência que tanto as crianças como os adolescentes acabam sendo vítimas desta ação, são aqueles que tinham que prover a proteção e acabam sendo os que mais praticam a violência.

Conforme a Sociedade Brasileira de pediatria (SPB) No Brasil, todos os dias, são notificados, em média, 233 agressões de diferentes tipos (física, psicológica e tortura) contra crianças e adolescentes com idades de até 19 anos. Somente no ano de 2017, a soma desses três tipos de registros contabilizados fora de 85.293 notificações, destes casos notificados $69,5 \%$ (59.293) são decorrentes de agressão física; 27,1\% (23.110) são decorrentes da violência psicológica; e 3,3\% (2.890) são decorrentes de episódios de tortura. Também a sociedade Brasileira de pediatria afirma que boa parte dessas situações acontece no ambiente doméstico ou tem como autores pessoas do círculo familiar e de convivência das vítimas. O gráfico abaixo do ministério da saúde mostra a situação por idade. 
Violência Física, Psicológica/Moral e Tortura praticada contra Crianças e Adolescentes (0 a 19 anos)

\begin{tabular}{|c|c|c|c|c|c|c|c|c|c|c|}
\hline \multicolumn{11}{|c|}{ VIOLÊENCIA FÍSICA } \\
\hline Faixa Etária & 2009 & 2010 & 2011 & 2012 & 2013 & 2014 & 2015 & 2016 & 2017 & Total \\
\hline Menor de 1 & 472 & 837 & 1.339 & 1.774 & 1.705 & 1.511 & 1.742 & 1.643 & 2.886 & 13.909 \\
\hline $1 \mathrm{a} 4$ & 884 & 1450 & 1.917 & 3.028 & 2.885 & 3.329 & 3.442 & 3.699 & 4.247 & 24.881 \\
\hline 5 ag & 1.291 & 2016 & 2.709 & 3.975 & 3.922 & 4.182 & 4.522 & 4.696 & 5.235 & 32548 \\
\hline 10 a 14 & 2.279 & 4.117 & 6.136 & 8.575 & 9.669 & 10.215 & 10.140 & 10.741 & 13.372 & 75.244 \\
\hline 15 a 19 & 4.164 & 7.437 & 12.668 & 18.992 & 22.368 & 24.426 & 25.755 & 27.307 & 33.553 & 176.670 \\
\hline Total & 9.090 & 15.857 & 24.769 & 36.344 & 40.549 & 43.663 & 45.601 & 48.086 & 59.293 & 323.252 \\
\hline \multicolumn{11}{|c|}{ VIOLÊNCIA PSICOLÓGICA OU MORAL } \\
\hline Faixa Etária & 2009 & 2010 & 2011 & 2012 & 2013 & 2014 & 2015 & 2016 & 2017 & Total \\
\hline Menor de 1 & 132 & 300 & 420 & 477 & 548 & 405 & 520 & 487 & 991 & 4.280 \\
\hline 1 a 4 & 570 & 802 & 1.107 & 1.445 & 1.530 & 1.647 & 1.757 & 2.018 & 2.304 & 13. 180 \\
\hline 5 a & 1.047 & 1.658 & 2.244 & 2.948 & 3.131 & 3.044 & 3.401 & 3.693 & 3.798 & 24.964 \\
\hline 10 a 14 & 1.420 & 2495 & 3.621 & 4.703 & 5.441 & 5.465 & 5.499 & 5.761 & 6.610 & 41.015 \\
\hline 15 a 19 & 1.156 & 2093 & 3.547 & 5.177 & 6.225 & 6.973 & 7.768 & 7.714 & 9.407 & 50.060 \\
\hline Total & 4.325 & 7.348 & 10.939 & 14.750 & 16.875 & 17.534 & 18.945 & 19.673 & 23.110 & 133.499 \\
\hline \multicolumn{11}{|c|}{ TORTURA } \\
\hline Faixa Etária & 2009 & 2010 & 2011 & 2012 & 2013 & 2014 & 2015 & 2016 & 2017 & Total \\
\hline Menor de 1 & 22 & 41 & 61 & 65 & 71 & 55 & 74 & 80 & 138 & 607 \\
\hline 1 a 4 & 51 & 96 & 83 & 123 & 139 & 168 & 185 & 235 & 300 & 1380 \\
\hline 5 a & 110 & 160 & 193 & 231 & 268 & 260 & 296 & 356 & 418 & 2292 \\
\hline 10 a 14 & 147 & 267 & 367 & 471 & 510 & 512 & 498 & 577 & 791 & 4. 140 \\
\hline 15 a 19 & 143 & 272 & 508 & 630 & 729 & 739 & 855 & 889 & 1.243 & 6.008 \\
\hline Total & 473 & 836 & 1.212 & 1.520 & 1.717 & 1.734 & 1.908 & 2.137 & 2.890 & 14.427 \\
\hline
\end{tabular}

Para Azevedo e Guerra, a violência não é um problema de uma minoria somente, mas ela abrange muito mais do que um grupo pequeno ela acontece em todos os lugares, onde existir pessoas e relações ela se fará presente, acontece sempre, ocorre com qualquer pessoa ou grupo de pessoas independente de posses ou de instrução educacional, se faz presente em todas as gerações e seu alcance é universal.

Em síntese, a violência doméstica contra crianças e adolescentes:

É uma violência interpessoal; é um abuso do poder disciplinador e coercitivo dos pais ou responsáveis; é um processo de vitimização que às vezes se prolonga por vários meses e até anos; é um processo de imposição de maus-tratos às vítimas, de sua completa objetalização e sujeição; é uma forma de violação dos direitos essenciais da criança e do adolescente enquanto pessoas e, portanto, uma negação de valores humanos fundamentais como a vida, a liberdade, a segurança; tem na família sua ecologia privilegiada. Como esta pertence à esfera do privado, a violência doméstica acaba se revestindo da tradicional característica do sigilo. (Azevedo \& Guerra, 1994:28)

\section{O LAR FOI PROJETADO PARA SER UM LUGAR DE SEGURANÇA}

A violência a que as crianças estão sendo submetidas ocorre principalmente, dentro de seus próprios lares, e é perpetrada, na grande maioria das vezes por aqueles que teriam o dever de protege-las, amá-las e respeitá-las, mas, no entanto, as maltratam, as violentam, rouba-lhes a inocência, a alegria, a liberdade, a própria vida e o prazer de viver.

Grande parte dos desaparecimentos de crianças e de adolescentes acontecem em decorrência dos maus tratos e de abuso sexual intrafamiliar, no Brasil são cerca de 30 mil por ano. Muitos deles fogem de seus lares para escapar das brutalidades vivenciadas em suas casas. Ao se refugiarem em outros ambientes como as ruas ficam expostos a todo tipo de marginalidade e, acabam caindo nas redes de exploração sexual, comercial e do tráfico de drogas.

A violência contra crianças e adolescentes está dividida em quatro grandes categorias: violência física; violência sexual; violência psicológica e negligência.

O primeiro estudo científico sobre violência física contra crianças foi realizado na França, em 1860, pelo professor Ambroise Tardieu, Presidente da Academia de Medicina de Paris. Ele estudou 32 casos de crianças que haviam sido submetidas a maus-tratos. Destas 32 
crianças, 18 foram a óbitos. Constatou-se que essas crianças apresentaram múltiplas e variadas lesões (fraturas, queimaduras, hematomas, equimoses), e que as explicações que os pais apresentaram não condiziam com as características das lesões encontradas.

Em 1962, nos Estados Unidos, Kempe e Siverman, dois médicos, estudaram o fenômeno do maltrato infantil doméstico, ao qual deram o nome de Síndrome da Criança Espancada, afirmando que:

Esta síndrome se refere usualmente a crianças da baixa idade que sofreram ferimentos inusitados, fraturas ósseas, queimaduras etc., ocorridas em épocas diversas, bem como em diferentes etapas e sempre inadequadas ou inconsistentemente explicadas pelos pais. $\mathrm{O}$ diagnóstico tem que se basear em evidências radiológicas dos repetidos ferimentos. (AZEVEDO E GUERRA, 1997, p.10).

Esta síndrome tem a sua predominância com crianças que nasceram em famílias de menos posses e que sofreram ou foram vitimadas pela ação e autoridade do mais forte quando atribuiu sobre elas seu domínio pelo viés da força. Na obra Pediatria Social - a Criança Maltratada, encontramos:

A criança maltratada apresentará a curto e a longo prazos consequências que dirão
respeito a seu físico, a sua mente e a sua relação com outras pessoas e com o mundo
em geral. A primeira e mais grave consequência dos maus-tratos é a morte. O ho-
micídio de crianças por seus pais (no sentido de cuidador) constitui importante fato
social. A segunda consequência, na hierarquia da gravidade, são o retardo mental
e o dano cerebral irreversível. As crianças maltratadas apresentam constantemente
retardo escolar. E isso é explicável por sua inadaptabilidade ao convívio com colegas,
ao retardo de linguagem e a sua própria adaptação ao sistema escolar. Outro fato im-
portante referente ao futuro das crianças maltratadas reporta-se as várias sociopatia,
com condutas antissociais variáveis, as quais irão culminar na adolescência: uso de
drogas e álcool, conduta criminal, roubo, fugas e piromania. As prisões estão repletas
de antigas crianças maltratadas. De não menos importância são, outrossim, as defor-
midades e as incapacitações físicas com os terapeutas, com eventuais pais adotivos
ou outros adultos, pois não confia em quem tente ajudá-la. (FARINATTI; BIAZUS
E LEITE, 1993, p.35-40).

\section{O CONTO A ILHA DOS GATOS PINGADOS E A REALIDADE VIVIDA EM NOSSO SÉCULO}

O conto "A ilha dos gatos pingados" mostra minorias segregadas, marginalizadas, oprimidas e até mesmo castigadas fisicamente e que dialoga com fatos ocorridos em nossas sociedades. J.J. Veiga traz temas da época vivenciadas em nossas sociedades atualmente que precisa ser discutido sempre, como os fatos ocorridos no estado de Goiás e Rio de Janeiro e noticiados pelas mídias na época.

No ano de 2008, uma menina de 12 anos foi resgatada pela polícia de um apartamento situado em uma área nobre de Goiânia. Ela foi encontrada amordaçada e acorrentada na área de serviço do apartamento de uma empresária que a torturava diariamente, além de obrigá-la a executar serviços domésticos, configurando crime de exploração infantil.

Em 2010, no Rio de Janeiro, uma procuradora aposentada foi condenada a oito anos e dois meses de prisão pelo crime de tortura contra uma menina de 2 anos que estava sob sua guarda provisória à espera de adoção. 


\section{DISCUTINDO OS TEMAS ATUAIS NA PERSPECTIVA LITERÁRIA.}

Neste sentido, o conto "A ilha dos gatos pingados" traz um tema muito atual: a violência cometida contra crianças e os adolescentes.

Neste conto o narrador traz à lembrança fatos de uma amizade que envolve crianças e adolescentes, em uma sociedade dominadora da época o mundo dos adultos, onde as crianças e os adolescentes são marginalizadas quando não existe no ambiente do lar a figura do pai protetor da família, e todos os que se aproximava deste lar tentariam dominar os mais fracos.

$\mathrm{Na}$ descrição o narrador, apresenta a história de amigos que diante da situação vivida por Cedil (um personagem que sofre a violência dentro do lar) o narrador apresenta em detalhes uma ilha afastada do vilarejo em que residem. O conto apresenta o personagem Cedil, que tem uma irmã cujo nome é Milila, este por sua vez sofre bastante por conta dos maus tratos empreendidos por Zoaldo (é o personagem que executa a violência), namorado de sua irmã e "usurpador do poder paterno, que usa de violência para com o menino". (VEIGA, 1986, p. 29). A situação fica ainda mais intolerável por causa da aceitação da mãe de Cedil (este personagem tem suas características de uma pessoa passiva diante da violência que seu filho sofre, ela não se posiciona). Ele, por sua vez, decide refugiar-se em uma ilha e conta com a cooperação de seus amigos. Os amigos são muito limitados em proporcionar ajuda ao sofrimento e a dor provocada pela violência praticada pela tirania dos adultos.

A narrativa se inicia com a voz de um personagem-narrador lembrando-se do amigo Cedil (que desaparecera e não sabe onde o encontrar), pondera as suas decisões sobre o retorno de seu amigo caso não retorne para os encontros com os demais na ilha; detalha a violência pela qual seu amigo passara na maior parte do conto, passa pelo ápice e termina com a fuga do menino. O narrador abre o conto com o seguinte parágrafo:

Já sei o que vou fazer. Se Cedil não voltar até o fim do ano, vou-me embora para o sítio de minha avó. Lá eu vou ter uma bezerra para tirar cria, um cavalinho pra montar e muitas coisas pra fazer o dia inteiro. É melhor do que ficar aqui feito bobo, pensando toda a vida na ilha, nos brinquedos que a gente brincava, nas coisas que Cedil e Tenisão diziam, e até nos sustos que passávamos, como no dia em que a jangada quase afundou com nós três (VEIGA, 1986, p. 27).

As lembranças do passado vividos pelo narrador personagem trazem recordações na esperança de poder rever seus amigos, principalmente o Cedil que foi o que mais sofreu com as injustiças praticadas no ambiente do lar.

Na obra "Mil Platôs" (1997), de Gilles Deleuze e Félix Guattari os autores levantam suas teorias a respeito dos espaços lisos e espaços estriados. Essas teorias aplicam-se em várias instâncias de nossas sociedades, desde o modelo (DELEUZE, 1997) (LURKER, 2003) (CARPENTIER, 1967) (BORGES FILHO, 2007) (SILVEIRA ALBERTON, 2005) marítimo, passando pelo modelo físico, matemático, estético, eles defendem que tanto no espaço liso quanto no estriado há linhas de vetores e pontos, sendo que no espaço estriado o trajeto subordina-se aos pontos, ao passo que no espaço liso os pontos subordinam-se ao trajeto:

[...] o espaço liso é direcional, e não dimensional ou métrico. O espaço liso é ocupado por acontecimentos ou necedades, muito mais do que por coisas formadas e percebidas. É um espaço de afectos, mais que de propriedades. É uma percepção háptica, mais do que óptica. Enquanto no espaço estriado as formas organizam uma 
matéria, no liso materiais assinalam forças ou lhes servem de sintomas. É um espaço intensivo, mais do que extensivo, de distâncias e não de medidas. Spatium intenso em vez de Extensio. Corpo sem órgãos, em vez de organismo e de organização. Nele a percepção é feita de sintomas e avaliações mais do que de medidas e propriedades. (DELEUZE; GUATTARI, 1997, p. 162-163, grifos dos autores).

A ilha servia como espaço liso, espaço das sensações, afetos e sentimentos e não das medidas ou propriedades. Borges Filho ressalta o espaço quando cita a palavra "topopatia", ou seja, "a relação sentimental, experiencial, vivencial existente entre personagens e espaço".

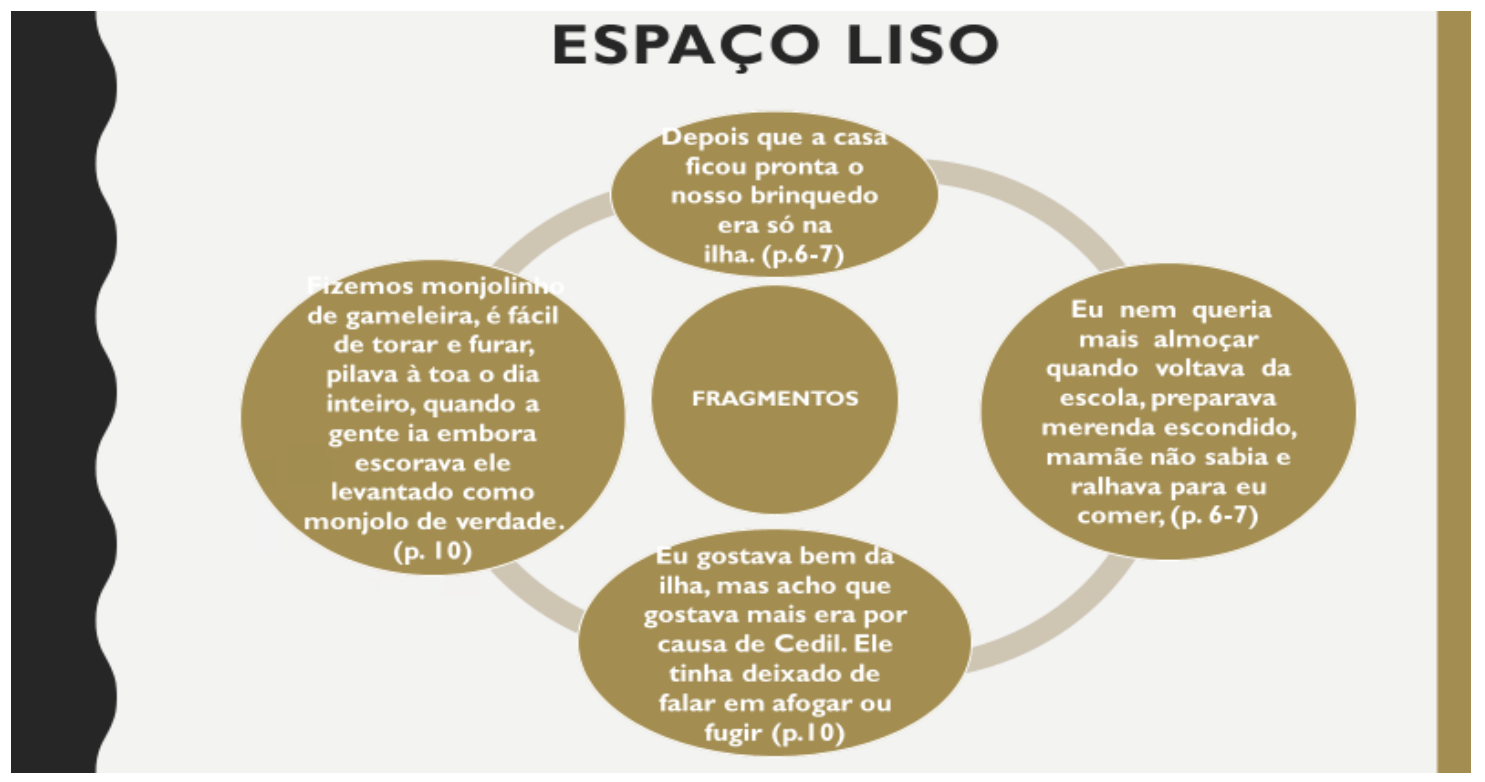

Figura 1: Espaço liso em à ilha dos gatos pingados

Borges Filho também destaca que essa relação entre o personagem e o espaço pode se desenvolver a partir duas figuras. Na primeira, há uma relação positiva entre os elementos espaço e personagem: "A personagem sente-se bem no espaço em que se encontra, o espaço é benéfico, construtivo, eufórico. Nesse caso, temos a topofilia²." (BORGES, 2007, p. 159). Em contrapartida, temos que "a ligação entre o espaço e o personagem pode ser de tal maneira prejudicial que a personagem sente mesmo asco pelo espaço. É um espaço maléfico, negativo, disfórico. Nesse caso, temos, então, a topofobia ${ }^{3 " \prime}$ (BORGES, 2007, p. 158).

Cedil não sentia aversão pelo seu lar, mas o seu temor desse local provinha a medida em que ele era ocupado também por Zoaldo. a topofilia que Cedil desenvolve em relação à ilha é de um grau tão intenso que ele se sente ainda mais feliz nela quando Zoaldo ausenta-se da cidade: "Eu gostava bem da ilha, mas acho que gostava mais era por causa de Cedil. Ele tinha deixado de falar em afogar ou fugir, decerto porque Zoaldo estava viajando [...]" (VEIGA, 2015, p. 33).

2 É descrito como sendo "o ele afetivo entre a pessoa e o lugar ou ambiente físico".

3 Ter aversão a ambientes naturais, sentir horror em atividades como acampamento em áreas naturais. 


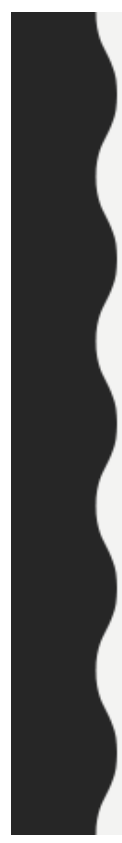

\section{ESPAÇO ESTRIADOS}

\section{FRAGMENTOS}

No primeiro dia fincamos as estacas da casa, amarramos as traves e cortamos uma braçada de varas para trançar as paredes.
Cedil queria fazer uma parede de qualquer jeito, com ramo de assa-peixe mesmo, só pra poder dormir a primeira noite.

Figura 2: O espaço estriado em o conto dos gatos pingados

Segundo (PAES 2005, p. 60) "O espaço estriado É um espaço limitado em suas divisões, às que correspondem direções constantes, separadas por fronteiras; é também um espaço limitador que restringe e exclui".

Nas histórias Veigueanas as crianças desenvolvem seus próprios códigos sociais que vão de encontro à lógica dos adultos. No conto "A ilha dos gatos pingados", o isolar-se na ilha e criar um outro mundo se motiva por conta das agressões físicas sofridas por Cedil dentro de sua casa: "A ideia de brincar na ilha foi motivado para evitar que Cedil tirasse toda a ideia de fuga ou suicídio que ele vinha projetando para aliviar as dores da violência que ora sofria por parte do namorado da irmã. "Cedil sofria muito, todo namorado de sua irmã Milila achava de ter controle sobre ele, o garoto nem podia brincar direito, vivia constantemente sendo vigiado". (VEIGA, 2015, p. 29).

No conto fica explícito que Cedil não tinha pai, então qualquer candidato que namorasse sua irmã achava que o poder paterno em relação a ele os pertencia. Zoaldo, o namorado que aparece no conto, não só vigiava Cedil, como praticava sobre ele atos de violência, a cada ato involuntário ou de desobediência.

O narrador-personagem destaca que nos primeiros dias do namoro da irmã de Cedil Zoaldo deu uma surra em Cedil por causa de uma malcriação que ele fez para Milila. Cedil estava brincando com outros meninos no barranco perto de casa. Milila chegou na janela e o chamou. Ele por sua vez disse que logo estaria entrando e permaneceu brincando. Ela retornou a chamá-lo e desta vez, ele disse para não amolar. Mediante a sua atitude Zoaldo desceu a calçada da casa e veio em direção a ele, parecia que ia embora. Mas quando passou perto de Cedil deu um bote e agarrou o coitado pelo cangote ${ }^{4}$, levou para dentro de casa debaixo de tapa ${ }^{5}$ e lá ainda bateu com o cinturão. "[...] depois disso Zoaldo não deixou mais Cedil ter descanso. Vivia mandando o coitado na rua fazer isso e aquilo, levar e buscar o cavalo no pasto, e volta e meia enfiava o couro nele. Dizia que era para desasnar (VEIGA, 2015, p. 30).

4 Palavra nordestina que significa pescoço

5 Golpe no rosto, bofetada, mãozada na cara. 


\title{
A ILHA PROPORCIONA UM ESPAÇO QUE O VIOLENTADO NÃO POSSUÍA
}

A importância do espaço da ilha. Espaço do lúdico e das leis criadas por crianças, uma nova sociedade floresce não mais de acordo com os ditames e regras do mundo adulto. $\mathrm{Na}$ ilha não há espaço para surras ou desmandos, muito embora ainda prevaleçam certas regras, como limpar a casa, organizar os brinquedos e buscar comida. Ainda assim prevalece o lúdico e a tranquilidade. Apesar das regras a ilha proporcionava vida, alegria, contentamento e brincadeira longe da tirania dos adultos.

Manfred Lurker (2003) observa em seu "Dicionário de simbologia": "Devido à sua localização isolada, muitas vezes de difícil acesso, as ilhas são geralmente associadas ao mágico [...] e ao miraculoso" (2003, p. 337). O autor ainda sinaliza que as ilhas também representam, na literatura, fugas em direção a paraísos aparentes.

$\mathrm{Na}$ narrativa de Veiga, a ilha promove uma experiência revitalizadora no sentido de oferecer a Cedil um lugar no qual ele pudesse ser o que é - uma criança que, como tal, não aceita os normas do mundo adulto regido por horários e regras muitas vezes incompreensíveis e contraditórios.

Neste conto Veiga nos apresenta o cuidado e a proteção que a amizade proporciona aquele que é torturado, neste caso Cedil, seus amigos o levam para o espaço da ilha, até como forma de evitar que ele fugisse ou tentasse o suicídio, uma vez que esses eram seus planos. Após atravessarem uma densa mata, os garotos se apoderam de um lugar que seria só deles, até mesmo por conta das dificuldades de se chegar à ilha:

Lá ninguém ia, o mato era fechado na beira da água, mas varando o mato o resto era limpo, dava muito cará e ${ }^{6}$ sangue-de-cristo. Não tinha era canoa, a que costuma ter tinham tirado, com certeza justamente pra menino não atravessar. $O$ jeito era fazer uma jangada de toro de bananeira (VEIGA, 2015, p. 32).

Neste espaço povoado por crianças, é natural que nesse local floresçam as fantasias e brincadeiras. E é através de uma brincadeira envolvendo o nome da ilha, que se manifesta a vinculação do conto com o realismo mágico:

\begin{abstract}
A ilha não tinha nome, era tratada só de ilha. Tenisão disse que carecia de dar nome, mas não achamos nenhum que prestasse. [...] Tenisão disse que o bichinho mais bonito do mundo inteiro, até nacional, e o mais custoso de achar, era o gato pingado; tinha uns até pingados de ouro, e esses então nem se fala. Eu não sabia que tinha esse bicho, Cedil também não, mas mostrou logo influência. Disse que se a gente juntasse dinheiro vendendo banana do quintal de cada um, quem sabe se não podia comprar um casal e tirar cria na ilha? Aí ficava sendo a ilha dos gatos pingados (VEIGA, 2015, p. 33).
\end{abstract}

\section{A ILHA PROPORCIONOU UM ESPAÇO MÁGICO E MARAVILHOSO}

Mágico ou maravilhoso? Como a literatura se apropria destes termos e a eles acrescenta a palavra realismo? O que ocorre de tão proeminente para que a literatura se nutra de uma determinada realidade e a partir dela componha termos complexos (realismo mágico e realismo maravilhoso) e difíceis de serem explicados? Para o crítico literário Alejo Carpentier na obra "Literatura do Maravilhoso" (1987, p. 140) ele pressupõe que a sensação do maravilhoso

6 Arbusto de até 2 metros ( Sabicea cana) da fam. das rubiáceas, nativo do Brasil (PI, GO a SP), com flores pálidas, axilares, e bagas globosas, de casca lanosa, esbranquiçada, e polpa roxa e adocicada; sangue-de-nosso-senhor, velame. 
admite uma fé. Somente os que possuem fé e a capacidade de levá-la a todos os setores da realidade, podem crer que santos curam doenças, que pessoas se transformam em lobisomens ou que milagres possam alterar uma realidade. Enquanto para o escritor Marcel Schneider na littérature fantastique (na obra literatura fantástica):ele afirma que "O fantástico explora o espaço do interior; tem muito que ver com a imaginação, com a angústia de viver e a esperança de salvação" (págs. 148-149).

Desta forma Carpentier utiliza a expressão "realismo maravilhoso americano" não para historiar um mundo idealizado ou fantasiado pelo escritor, mas para o registro de uma cultura que sempre ressaltou sua fé: "Pisava eu em uma terra onde milhares de homens que ansiavam por liberdade acreditaram nos poderes licantrópicos de Mackandal, a ponto de essa fé produzir um milagre no dia de sua execução" (CARPENTIER, 1987, p. 141).

De acordo com os estudos realizados por Tzvetan Todorov, o fantástico abrange o envolvimento não apenas do narrador, mas também das personagens: O fantástico recomenda, pois, uma integração do leitor com o mundo dos personagens. [...] A percepção desse leitor implícito se registra no texto com a mesma precisão com que o estão os movimentos dos personagens (TODOROV, 2004, p. 37).

Veiga nos mostra que a ilha representa, muito apropriadamente, um espaço que não segue as leis daquela sociedade. Não há um poder paterno ou alguém que o represente, que obrigue as crianças a serem obedientes, do contrário elas seriam fisicamente castigadas. Daí que gatos pingados de ouro não são quase nada se comparados à situação insólita vivenciada por Cedil ao sofrer maus tratos do cunhado. Eles se apoderam da ilha. Não apenas por descobrirem e explorarem um lugar que seria o baluarte contra a violência, mas pelo fato de que eles deram um nome a um local virgem, não explorado por mais ninguém. (VEIGA, 2015)

\section{A ILHA PROPORCIONAVA ALÍVIO A DOR QUE O MUNDO ADULTO CAUSAVA A IINFANCIA}

Qual foi o real motivo de Cedil se refugiar no espaço da ilha? Além dele dar vazão às brincadeiras típicas de meninos de sua idade, ele precisava de um lugar no qual não receberia ordens, não sofreria maus tratos muito menos seria humilhado pelos dominadores. O interesse era encontrar um espaço que distinguisse um contraponto às opressões por ele vivenciada em sua casa, e isto era o que a ilha proporcionava. Natural, portanto, que o nome fosse ao encontro dessa necessidade, desse local que só existia para Cedil e seus amigos queridos que também compartilhavam sua tristeza e sua dor: "Eu gostava bem da ilha, mas acho que gostava mais era por causa de Cedil" (VEIGA, 2015, p. 33).

A amizade infantil além de criar também descobriu um mundo de encanto e magia que proporcionou alivio a tortura praticada pelo mundo dos adultos, neste caso representado por Zoaldo namorado de Milila sua irmã, que constantemente o torturava com violência e ao mesmo tempo o forçava a fazer trabalhos que deveria ser praticado somente por pessoas adultas. Mas, este novo mudo que haviam descobertos cheio de encanto e magia estavam chegando a um final desastroso, e a magia que a ilha proporcionava perderia o seu encanto quando outros garotos descobrem este local que pertenciam somente aquele grupo pequeno. Que teriam seus sonhos e suas construções destruídos de uma forma violenta. A partir daí não há mais ilha, não há espaço do refúgio e, portanto, o nome ilha dos gatos pingados fica na memória dos garotos que um dia foram felizes naquele lugar. 


\section{O MUNDO INFANTIL VIVE UMA AMEAÇA CONSTANTE EM NOSSA GERAÇÃO}

Segundo a temática apresentada pelo escritor J.J. Veiga que trata da violência doméstica praticada no âmbito familiar, lugar este que deveria proporcionar segurança para os seus membros se transformou em um único lugar onde só gera dor e sofrimento.

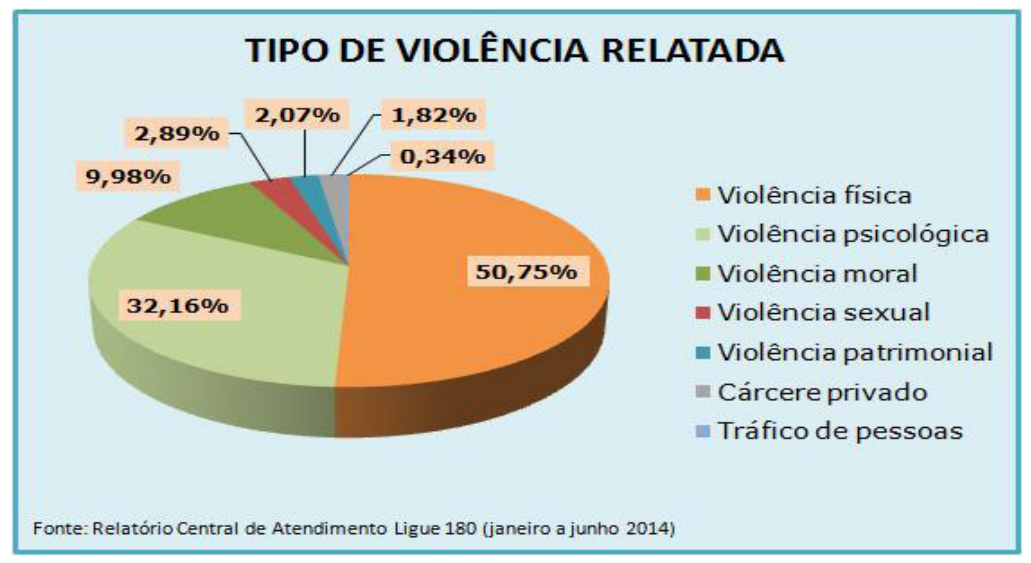

Figura 3 Mapa da violência em nossos dias

No mapa acima a predominância é a violência física causadora por muitos fatores na sociedade, onde o grupo se encontra inserido e este tipo de violência acarreta distúrbios psicológicos no vitimado, que segundo o gráfico tem dimensões assustadores e quando isto acontece é difícil e lento o processo de recuperação.

Vale destaca que a geração de hoje vive outros problemas que afeta o mundo infantil vivido em nossos dias, como: o trabalho escravo e o casamento forçado. Segundo uma matéria do jornal do Brasil, a matéria destaca: um estudo divulgado recentemente mostra que o Brasil é o $4^{\circ}$ país no mundo com maior índice de casamentos de crianças e adolescentes meninas, o que representa mais um passo atrás no que diz respeito aos princípios básicos dos direitos humanos. Essa realidade chega a atingir mais de 554 mil meninas com idade de 10 a 17 anos, enquanto no Brasil existe mais de 65 mil delas com idade entre 10 e 14 anos, segundo estudo do banco Mundial.

O lar dever deve ser o local onde proporcione segurança e amor, mas muitas vezes não é isto o que acontece e cada vez mais as crianças e os adolescentes se sentem ameaçadas por aqueles que poderiam lhes proporcionar segurança e amor, acabam tendo que sair de seu lar e procurar refúgio nas ruas, onde o perigo se torna ainda maior. Muitas das crianças, no caso do sexo feminino acabam contraindo casamento e segundo dados ficou constatado que no Brasil, a região com mais filhos de mães adolescentes é o Nordeste (180.072 - 32\%), seguido da região Sudeste (179.213 - 32\%). A região Norte vem em terceiro lugar com 81.427 (14\%) nascidos vivos de mães entre 10 e 19 anos, seguido da região Sul (62.475 - 11\%) e Centro Oeste $(43.342-8 \%)$. O Brasil ocupa a quarta colocação no mundo de países onde o casamento infantil tem aflorado, ficando atrás de Nigéria, Bangladesh e Índia.

Outro ponto destacado pela matéria é o trabalho escravo envolvendo menores de idade. No mundo existe cerca de 152 milhões de crianças que estão sendo forçadas a trabalho infantil. Enquanto aqui no Brasil existem 60,5 milhões de crianças até 19 anos e elas estão divididas por regiões: A maior parte dessa população está na região Sudeste, onde vivem cerca de 18,6 milhões de crianças e adolescentes. No entanto, é nas regiões Norte e Nordeste onde 
a proporção de crianças e adolescentes - comparada à população total - é mais elevada. E é justamente lá que estão os piores indicadores sociais.

Dentre os setores no Nordeste destaca-se o tipo de trabalho onde as famílias empregam seus filhos menores: nos canaviais, na lavoura bem como no manuseio da castanha de caju. A necessidade das famílias leva a perca de sua infância. No Nordeste apesar da infância haver sido arrancadas das crianças elas ainda convive com o mal que a sociedade adulta causa na saúde destas crianças. As crianças que trabalham com a quebra de castanhas de caju têm que conviver com danos praticados em sua saúde, pois o óleo presente nestas castanhas é um ácido, mais conhecido como LCC (liquido da castanha de caju) tem em sua composição 7ácido anacárdico, que corrói a pele, provoca irritações e queimaduras químicas. Este tipo de atividade destrói totalmente a saúde das pessoas e destrói sonhos de uma geração futura, segundo pesquisas realizadas pelo médico Salim Amed Ali, autor de diferentes estudos sobre doenças ocupacionais para a Fundação Jorge Duprat Figueiredo de Segurança e Medicina do Trabalho (Fundacentro), do Ministério do Trabalho e Emprego. A perda da identidade não é permanente. Com o tempo, as digitais voltam se a pessoa se afastar da atividade.

Para Marcílio (1998, p.50), o Brasil antecipa os preceitos da Convenção reconhecendo a criança como indivíduo de direitos na Constituição de 1988, conforme o que dispõe o artigo 227 da Carta Magna:

É dever da família, da sociedade e do Estado assegurar à criança e aos adolescentes com absoluta prioridade, o direito à vida, à saúde, à alimentação, à educação, ao lazer, à profissionalização, à cultura, à dignidade, ao respeito, à liberdade e à convivência familiar e comunitária, além de colocá-la a salvo de toda forma de negligência, discriminação, exploração, violência, crueldade e opressão.(Brasil, 1988, Art.277).

É um direito outorgado pela constituição federal de 1988 para crianças e adolescentes o direito de formação educacional bem como todas as garantias de subsistência para a sua formação educacional e profissional. E os órgãos governamentais e a família devem proporcionar.

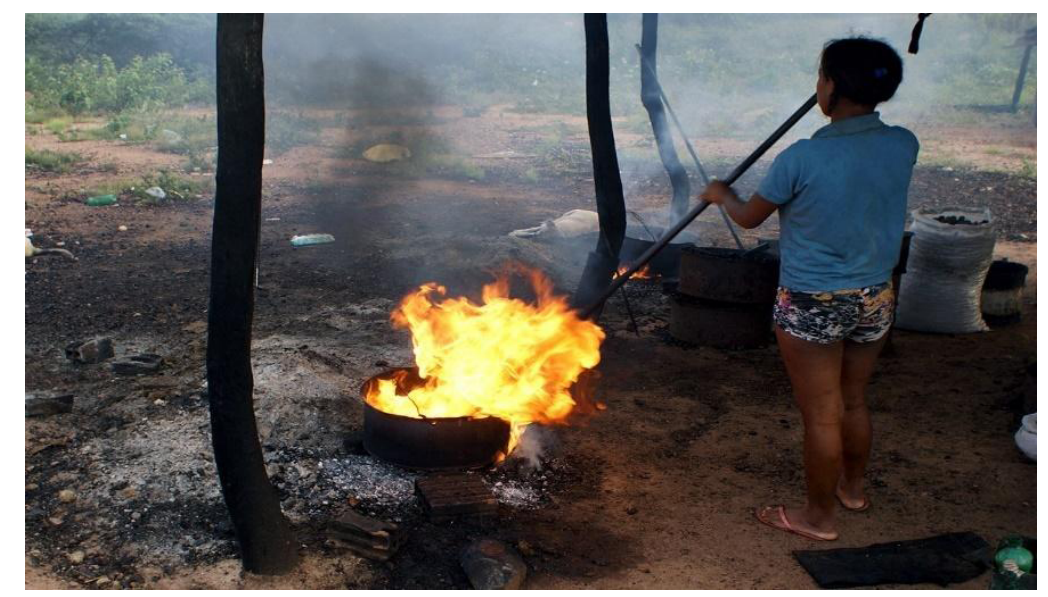

Figura 4 Processo da extração da castanha de caju

O processo de cozimento da castanha de caju é um método longo e requer um cuidado extremamente grande, e este trabalho sempre é realizado nas madrugadas, pois o calor escal-

7 O ácido anacárdico é um composto químico encontrado na casca da castanha de caju. Como ele está intimamente relacionado com urushiol, podendo também causar uma erupção cutânea alérgica em contato com a pele conhecida como dermatite de contato induzida por urushiol. O ácido anacárdico é um líquido amarelo. 
dante do Nordeste impossibilita de as pessoas ficarem próximos do fogo em um período do onde a temperatura é grande.

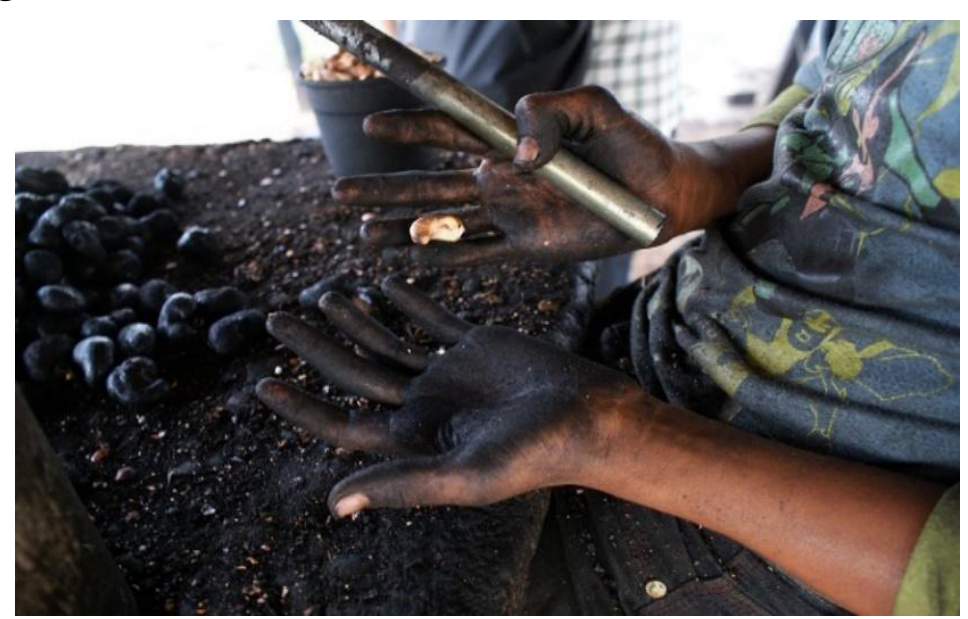

Figura 5 Quebra da castanha de caju

É mediante a quebra da castanha que as pessoas começam então a perder as digitais de seus dedos, mesmo depois do processo de limpeza, o ácido destrói totalmente as digitais dos dedos e prejudica outros órgãos do corpo e ainda afeta o meio ambiente.

\section{CONSIDERAÇÕES FINAIS}

A sociedade vem vivendo um período de intensa dificuldade, quando a violência tem dominado os lares e promovendo o terror no meio das famílias mediante o grau de violência que as crianças estão vivendo nestes lares, lares onde deveriam ser um local de segurança tem se tornado um lugar onde o terror tem se aflorado. O grupo que mais tem sido prejudicado por estas ações são as crianças e os adolescentes. Infelizmente tem se tornado casos que requeira a atenção das autoridades, pois a violência em que este grupo tem sofrido dentro do seu próprio lar provocado pela sociedade parece sem solução, medidas precisam serem tomadas para que isto não mais aconteça. Conscientizar seria uma saída para que estes tipos violências deixem de existir. Se a violência tem seu início na própria família, como trabalhar este tema.

A educação pode contribuir muito a formação de cidadãos para uma sociedade sadia, enquanto muitos meios de comunicação vêm deturpando e aniquilando a infância e a juventude com suas histórias floridas, enquanto a literatura por sua vez vem formando e informando e ao mesmo tempo construindo uma sociedade saudável. Cabe ao governo o detetor do poder mudar tudo que é prejudicial a sociedade de hoje, mas o que se veem é uma política passiva diante de tudo que acontece e sem perspectivas de criar políticas sociais que sejam saudáveis a vida.

O conto "a ilha dos gatos pingados" a mais de cinquenta e oito anos trata estes temas que envolve a violência doméstica e o bullying, e são temas bastante atuais que precisam serem abordados ou do contrário terão muitos problemas pela frente.

Enquanto a literatura tem formado e informado, onde estão os textos literário? muitos estão nas prateleiras das bibliotecas empoeiradas sem serem usadas e na maioria das vezes quando alunos são confrontados a respeitos de textos como este que foi abordado os alunos desconhecem. Quem hoje em nossa sociedade nunca sofreu bullying, nunca sofreram qual- 
quer tipo de violência domésticas, psicológica, sexual e outros? e quais foram as medidas tomadas?

É preciso haver mudanças, é preciso discutir estes temas com pais, professores, alunos, a sociedade e com os políticos que são os formadores das leis neste país, é preciso dar um basta nos veículos que dissemina estes tipos de práticas de comunicação.

Veiga é uma voz na literatura ao abordar temas tão vivos em nossa sociedade no século vinte e um a quase cinquenta e oito anos atrás e parece que nada mudou até agora.

Realmente a literatura informa bem como transforma, mas é preciso conscientizar. Conscientizar que em cultura é necessário respeitar os direitos de todos e toda criança tem direito, direito a vida, direito a educação e o direito de serem respeitados. O Norte e o Nordeste fazem parte do Brasil e devem serem respeitados como os demais estados que fazem parte da união. Direitos devem serem para todos e a educação de qualidade é um direito das crianças e dos adolescentes. A lei deve proteger todo mundo.

Em à ilha dos Gatos pingados o autor retrata a realidade vivida no século vinte e um, onde os direitos são desvalorizados; onde lares são oprimidos pelos mais fortes, pelos dominadores. Muitas vezes as famílias mais simples não têm força para lutar e acabam sendo oprimidos pelo que detêm o poder, como acontece com as famílias Nordestinas que em busca de uma condição melhor na região acabam sacrificando seus filhos menores para não morrerem pela escassez de alimentação. E a educação que é um direito que eles têm, sempre falta professores e a localização é grande para se deslocarem. É interessante proteger as crianças dos dominadores intelectuais, como o que aconteceu nos estados de Goiás e Rio de Janeiro onde foram maltratadas e usadas para tipos de serviços e ainda sendo acorrentadas. Direito e educação não podem ser tirados como também o seu mundo infantil com sonhos.

\section{CHILDREN'S FRIENDSHIP AND TYRANNY IN THE WORLD OF ADULTS IN "THE ISLAND OF PINGED CATS"}

ABSTRACT: In this article, the short story "The island of pinged cats" by the writer José Jacinto Veiga, when dealing with the theme brings a proposal for the novelistic aspect of magical Realism. Based on such inquiries, the work proposes to discuss the violence committed against children, as well as the tyranny of adults over them. Also, analyze whether the home is an environment that transmits security; it also suggests working on this story in the classroom to value the aesthetic aspects of the literary text and to interrelate them with the social and political aspects of a certain group. The work consists of bibliographic research of analyzes of the proposed short story / chronicle and of authors who discuss the problems presented. From this, it is concluded that the short story "The island of pinged cats" by J.J Veiga, in addition to promoting aesthetic pleasure in reading, can also open spaces for thematic discussions on controversial subjects such as: friendship, solidarity, violence that affects in humiliation and aggression.

KEYWORDS: Tale. Literature. Violence. Children.

\section{REFERÊNCIAS}

BORGES FILHO, O. Espaço e literatura: introdução à topoanálise. Franca: Ribeirão Gráfica e Editora, 2007.

CARPENTIER, A. El reino de este mundo. Mexico: Cia General de Ediciones S.A, 1967.

DELEUZE, G. G. F. Mil Platôs. Sao Paulo: 34, v. 5, 1997.

EMPRESÁRIA é condenada a pagar indenização a adolescente torturada. G1, Goiânia, 12 set. 2008. 
Disponível em:<http://g1.globo.com/Noticias/Brasil/0,,MUL758411-5598,00.html>. Acesso em: 20 ago. 2017.

LURKER, M. Dicionário de simbologia. 2. ed. Sao Paulo: Martins Fontes, 2003.

PAES, José Machado. Jovens e cidadania. In: Sociologia, problemas e práticas. N.49, 2005, p.53-70.! SILVEIRA ALBERTON, M. Violação da Infância Crimes Abomináveis. Porto Alegre: Age, 2005. TODOROV, T. Introdução à literatura fantástica. 3. ed. São Paulo: Perspectiva, 2008.

BRASIL. Constituição da República Federativa do Brasil: 1988 texto constitucional de 5 de outubro de 1988 com as alterações adotadas pelas Emendas Constitucionais n. 1/92 a 19/98 e pelas Emendas Constitucionais da Revisão n. 1 a 6/94. 10 ed. Brasilia: Câmara dos Deputados, Coordenação de Publicações. 